\title{
New tools to study the role of B cells in cytomegalovirus infections
}

\author{
Ari Waisman · Andrew L. Croxford · Filiz Demircik
}

Received: 15 February 2008 / Published online: 11 March 2008

(C) Springer-Verlag 2008

\begin{abstract}
B cells were previously shown to mediate partial protection against CMV infection, as in the absence of B cells, latently infected mice were more susceptible to virus reactivation. It remains unclear if this effect stems from the loss of B cells as antibody producers or as antigen presenting cells. To address this fundamental question, we propose to make use of new mouse models that allow conditional ablation of $\mathrm{B}$ cells or that allow for the generation of mice with B cells that are not able to produce antibodies.
\end{abstract}

\section{Short history of B cells and CMV infection}

Cytomegaloviruses (CMVs) are members of the herpesvirus family. CMVs show host species-specificity; for instance, human CMV (HCMV) and murine CMV (MCMV) infect humans and mice, respectively. Primary infection with HCMV or MCMV is controlled by the immune system and in particular cytotoxic T cells (CTLs) were shown to play a critical role (for a review see [1]). Like the other members of the herpesvirus family, CMVs cannot be entirely eliminated by the infected host, even if the immune system is intact. After the primary infection is controlled, CMVs remain in reservoirs in a state of latency. The cell types in which the virus persists are yet to be identified. In humans as well as in mice, reactivation of latent CMV can occur when the host is immunosuppressed. In immunocompromised or immunosuppressed patients, CMV reactivation can result in invasive CMV disease such

A. Waisman $(\varangle) \cdot$ A. L. Croxford · F. Demircik

1st Medical Department,

University of Mainz, Obere-Zahlbacherstr. 63,

55131 Mainz, Germany

e-mail:Waisman@uni-mainz.de as pneumonitis, esophagitis, encephalitis, hepatitis, pancreatitis, adrenalitis, gastritis, enteritis, colitis, and retinitis [2, 3]. HCMV is by far the most common infection in solid organ transplant recipients, with over half of the patients showing evidence of active infection (viral replication). In addition to the debilitating effects of direct, organ-specific syndromes such as bilateral interstitial pneumonia, disseminated CMV disease is widely believed to cause graft injury and shorten graft survival $[4,5]$. Much is known about the factors that control the primary CMV infection, but much less is known about how to control the reactivation of the virus, or in fact which cellular and humoral factors keep the virus inactive after the first infection is resolved.

Antibodies were found to have a protective role in mice infected with MCMV [6]. CMV-specific serum was administered to infected mice and was shown to partially protect the mice [7]. These results were confirmed by experiments where serum from infected C57BL/6 mice, but not naïve mice or B-cell deficient $\mu \mathrm{MT}$ mice, showed dramatically reduced virus titers in the salivary glands and blood of infected mice [8]. Moreover, when monoclonal antibodies were used in protection assays, it was found that protection from CMV infection correlates with affinity to CMV antigens: the antibodies with the higher affinity protected the mice much better than the antibodies with lower affinity [9]. To better understand the role of antibodies and B cells in MCMV infection, Jonjic and co-workers investigated CMV infection in the $\mu \mathrm{MT}$ mice that lack B cells. Using these mutant mice, it was possible to demonstrate that neither B cells nor antibodies are essential for the resolution of primary CMV infection [10]. Interestingly, it was found that reactivation from virus latency is the only situation where B cell or antibodies play a role, as virus reactivation results in higher virus titers in $\mu \mathrm{MT}$ mice compared to control mice, presumably because virus spread and 
dissemination is no longer blocked by antibodies [10]. As recurrent infection is thus apparently facilitated in $\mu \mathrm{MT}$ mice, these mice were used to study the role of different lymphocyte subsets in MCMV immune surveillance. $\mu \mathrm{MT}$ mice were infected with MCMV, and after the virus became latent, $\mathrm{T}$ cells and NK cells were depleted using antibodies. As early as three days after lymphocyte depletion, virus recurrence became detectable [11]. Further it was found that $\mathrm{T}$ cells are more important than NK cells in MCMV immune surveillance, as for the virus to be activated in $\mu \mathrm{MT}$ mice it was sufficient to delete $\mathrm{CD} 4^{+}$and $\mathrm{CD}^{+} \mathrm{T}$ cells [11]. Moreover, a recent work from the laboratories of Winkler and Mach [12] has shown that transfer of antigen experienced B cells, alone in mice that lack B and $\mathrm{T}$ cells (RAG deficient mice) was sufficient for protection to MCMV. These findings show that B cells and antibodies play a critical role in control of MCMV latency and that $\mathrm{T}$ cells are critical to keep the virus latent in the absence of B cells.

\section{$B$ cell depletion and $B$ cell-deficient mice}

How can we study the role of B cells in infections in general, or with a focus particularly on CMV infection? Over the last years, two main methods and mouse models were generated for such studies. The first involves the in vivo deletion of B cells using monoclonal antibodies. The first attempts were by using anti-IgM depleting antibodies [13]. These experiments led to $90-95 \%$ deletion of mature B cells, but did not result in plasma cell depletion. As a consequence, mice that have already developed a mature immune system were left with high levels of antibodies also after anti-IgM-mediated depletion, as plasma cells were shown to have a long lifespan [14]. Similarly, depleting antibodies directed to another B cell surface molecule, CD20, are currently used [15]. These antibodies deplete $\mathrm{B}$ cells more efficiently than anti-IgM antibodies, and importantly, can also model B cell depletion in humans, as the human antiCD20 antibodies are already in clinical use in different cancers $[16,17]$. Nevertheless, also these antibodies do not reach $100 \%$ depletion of $\mathrm{B}$ cells, but rather $95 \%$. Additionally, it is not possible to deplete plasma cells, which do not express the CD20 receptor.

In 1991, the group of Klaus Rajewsky introduced a new mouse model that contains a deletion in the genome that prevents the expression of IgM on the surface of developing B cells [18]. As a consequence, B cells did not receive the required signals for their development and the mice were devoid of these cells. These mice, termed $\mu \mathrm{MT}$, were used in many experiments to study how B cell deficiency affects the immune response. In particular, the $\mu \mathrm{MT}$ mice were used in different infection models [19, 20], including models of CMV infection as discussed above $[8,10,11]$. Because of the nature of the mutation introduced in the genome of $\mu \mathrm{MT}$ mice, these mice were found to be leaky, especially when crossed to the BALB/c genetic background. As $\operatorname{IgM}$ and $\operatorname{IgD}$ constant regions ( $\mu$ and $\delta$, respectively) are coded in the mouse on a bicistronic transcript, it is possible in rare cases for $\mathrm{B}$ cells to develop as $\operatorname{IgD}^{+}$, thus
Fig. 1 Loci of the B cell mutant mice. a A schematic representation of the IgH locus of wild type, IgMi, IgG1i and JHT mice. b In the IgMi mice, the first polyA signal, directly down stream of exon 4 was deleted. The second polyA site is located down stream of the membranal exons, and was not deleted. Therefore, this locus can code only for the mebranal-form of the constant region of the IgM antibody, and not the secreted form like the wild type locus
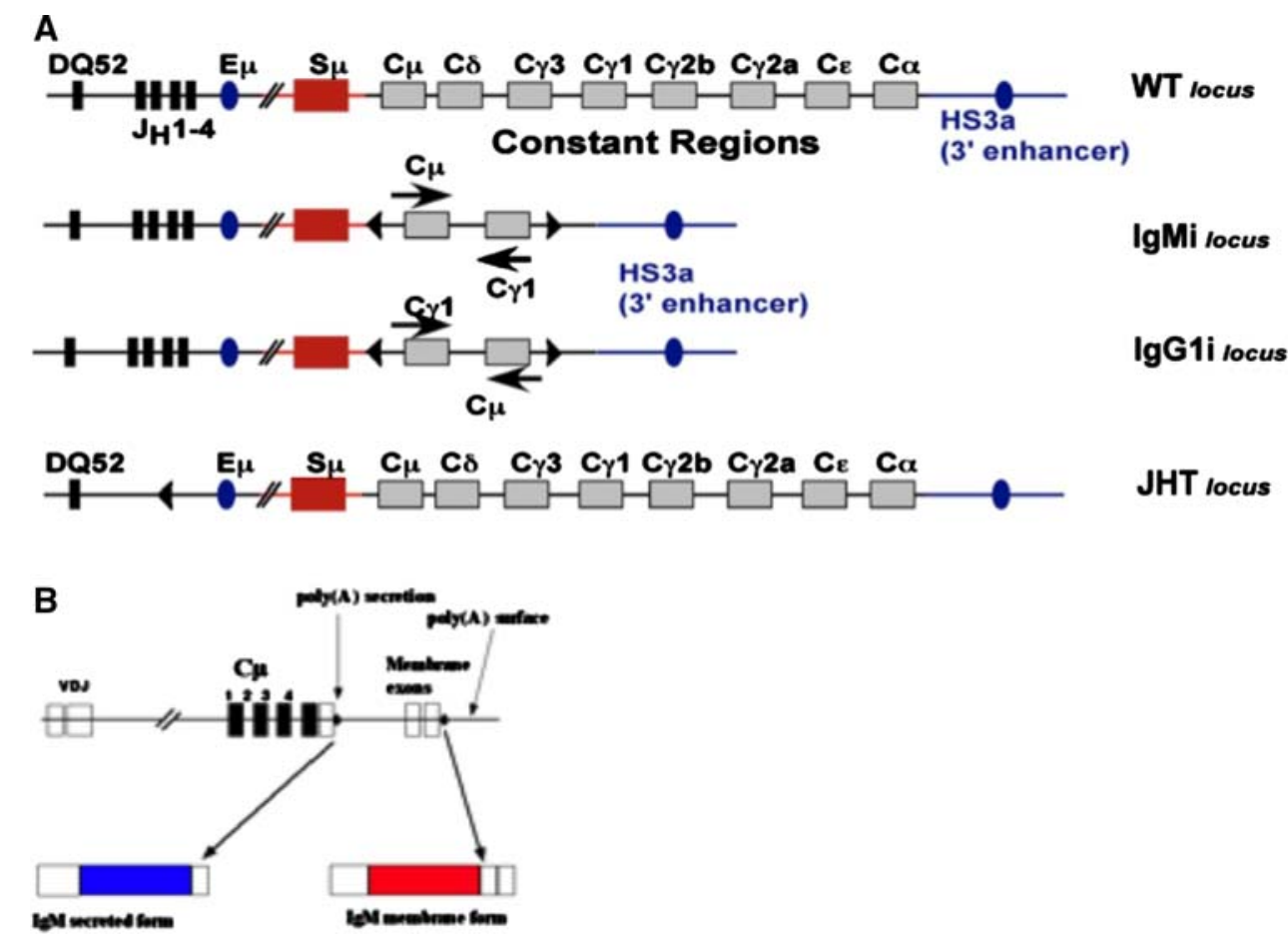
bypassing the need for IgM in B cell development. These $\mathrm{IgD}^{+} \mathrm{B}$ cells are rare in $\mu \mathrm{MT}$ mice [21], but nevertheless can give rise to $\mathrm{B}$ cells that subsequently go through the process of class-switch recombination and differentiate to plasma cells that eventually fill up the plasma cell compartment $[21,22]$. A better model to study the role of B cells in B cell deficient mice is the JHT mouse model (see Figs. 1, 2). These mice harbor a deletion of the JH minigenes [23], generated using the Cre-loxP system. They are truly devoid of B cells in all tested genetic backgrounds. Thus, the JHT strain is a more suitable model for studying immune responses in the absence of B cells. However, these mice also suffer from an inherent problem, namely their lack of B cells throughout the entirety of their development. It seems that B cells play a role in shaping the immune system, in particular in shaping the repertoire of $\mathrm{CD}^{+} \mathrm{T}$ cells [24]. It is therefore difficult to draw reliable conclusions on the role of $\mathrm{B}$ cells during infection if the $\mathrm{T}$ cell responses are compromised.

\section{New mouse models to study the role of $B$ cells in infectious diseases}

Diphtheria toxin (DT) is not toxic in mice when used in low concentrations, as mice do not express its high affinity receptor. Jung and colleagues have shown that if dendritic cells (DCs) are made to express the simian diphtheria toxin receptor (DTR) in a transgenic mouse, these DCs can be ablated when mice are injected with DT [25]. We have
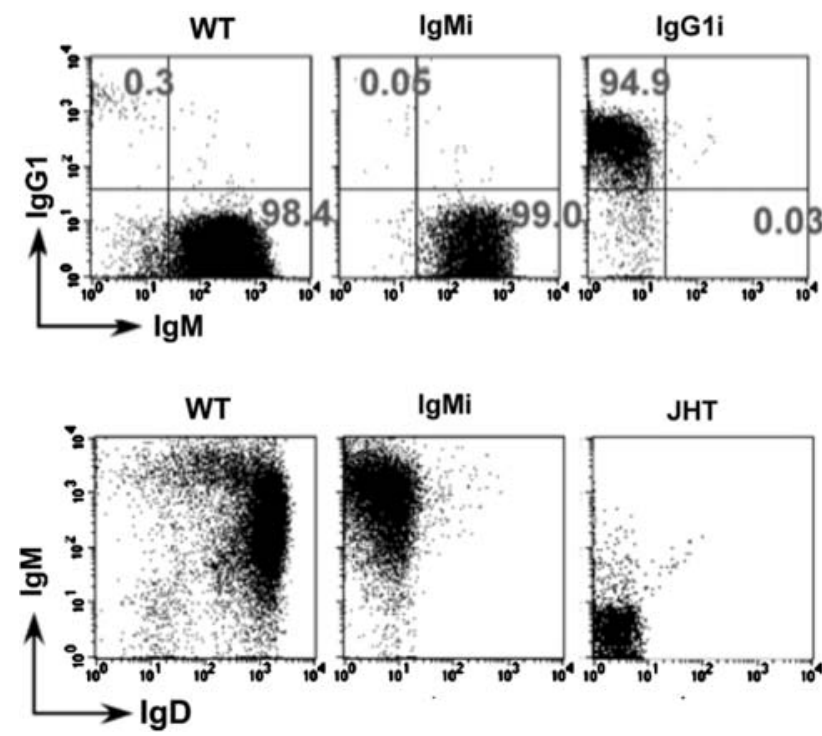

Fig. 2 B cell populations in different mutant mice. Shown are flow cytometry data from $\mathrm{CD} 19^{+} \mathrm{B}$ cells of wild type, IgMi and IgG1i mice. For JHT mice, which are devoid of B cells, all cells in the lymphocyte gate are shown. Cells were isolated from the spleen of the indicated mice and stained for CD19, IgM and IgG1 or IgD recently constructed a new murine system where the simian DTR is expressed following Cre-mediated recombination [26]. This new mouse strain is termed iDTR, as the expression of DTR is induced by the Cre-recombinase. Using this system, we were able to demonstrate that following multiple injections with DT, more than $98 \%$ of the B cells were depleted in mice expressing Cre recombinase under the CD19 promoter (see Fig. 3, adapted from [26]). The Crerecombinase is an enzyme that recognizes a specific sequence termed loxP. When this enzyme identifies two of these sequences in the genome, it is able to remove the DNA flanked by these loxP sites, and one of the loxP sites. The Cre/loxP system is a "genetic memory" system in that in every cell where Cre-recombinase was active in, like B cells in CD19-cre, DNA will stay recombined. In the case of the iDTR mice, this means that plasma cells, which are derived from $\mathrm{CD} 19^{+} \mathrm{B}$ cells but cease to express this receptor, do indeed still express DTR. Preliminary data from our laboratory indicates that also all B cells and B-cell derived cell types are depleted in CD19-cre/iDTR mice after administration of DT (F.D. and A.W., data not shown).

Thus, the iDTR mouse strain allows for the efficient depletion of B cells. Another advantage it has over depletion with B-cell specific antibodies is the lack of immunity to DT in the mouse. We have shown that repeated injection of mice with DT, even together with an adjuvant, does not result in the development of neutralizing antibodies [26]. This finding together with the relatively low price of DT compared to antibodies as well as the ease of its usage, make the iDTR a favorable mouse model for B cell ablation. As the iDTR mice were done using embryonic stem cells of the C57BL/6 genetic background, they are available in this pure genetic background that facilitate the investigation of immune responses.

The JHT mouse model allows for the study of the role of $\mathrm{B}$ cells and antibodies in different infectious diseases. What it does not allow for is the differentiation of the role of $\mathrm{B}$ cells versus secreted antibodies in these responses. For that, one needs a mouse strain in which B cells can develop, but are devoid of antibodies. For this purpose, we have generated the IgMi mouse strain [27]. As can be seen in Figs. 1 and 2, we have generated a mouse strain where the polyA responsible for the secreted form of antibodies is deleted in the genome of the mice, allowing coding only of membrane immunoglobulin (the B cell receptor). The constant region coding for the heavy chain of IgM (termed $\mathrm{C} \mu$ ) contains two polyA sites. The first, which we deleted in the genome of the IgMi mice is essential for the maturation of the RNA that is transcribed to the secreted form of the IgM heavy chain (secreted IgM antibodies). The second polyA which we did not delete, is the one responsible for the maturation of the membrane-form of the IgM heavy chain (IgM B cell receptor). The resulting IgMi mice (which are available in 
Fig. 3 The iDTR mice. a A schematic representation of the iDTR mouse locus. R26-Pro indicates the ROSA26 promoter. b CD19-Cre/iDTR mice and control mice were injected with equal doses of diphtheria toxin. Shown are cells isolated from spleen $(S p l)$ or lymph nodes $(L N)$. (Figure adapted from [26])

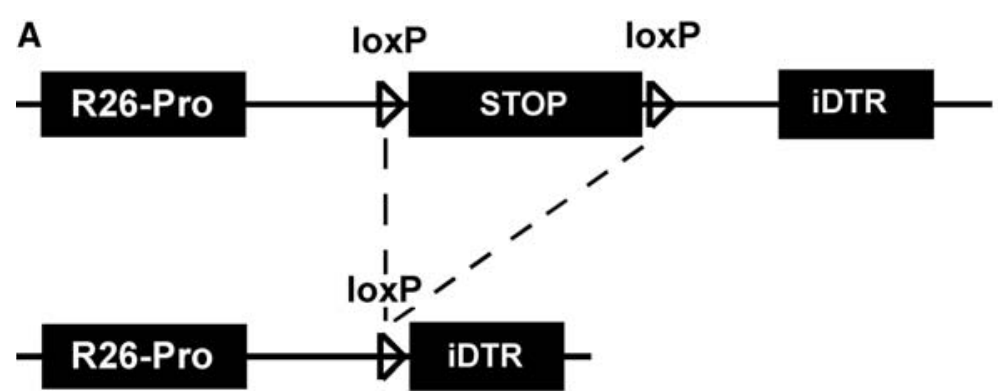

B

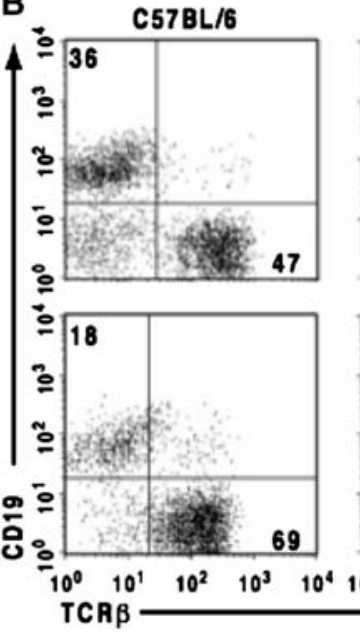

CD19-Cre
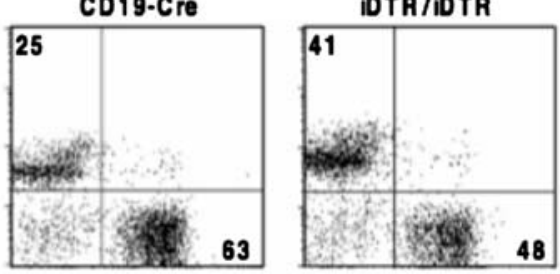

CD19-Cre/iDTR
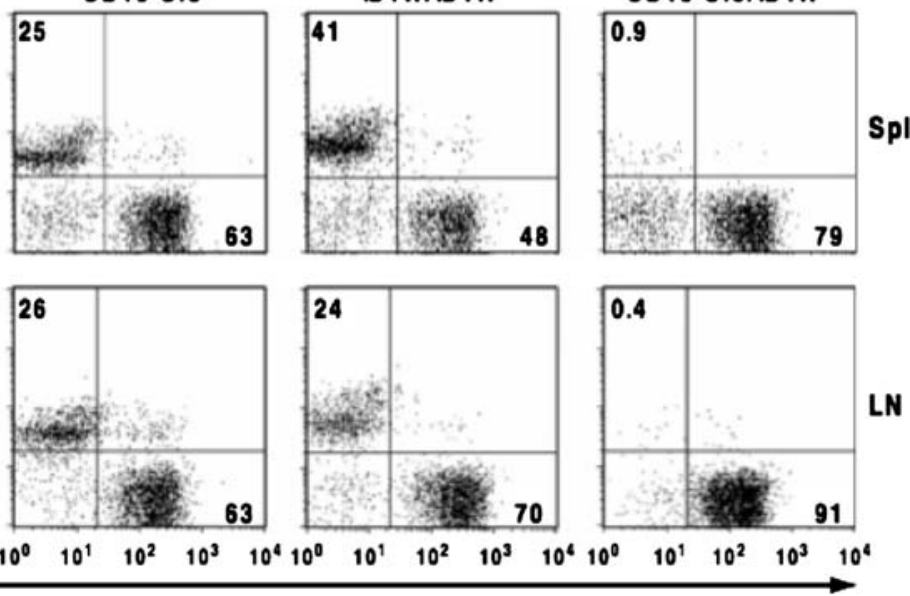

C57BL/6 and BALB/c genetic background) develop B cells that express IgM as the B cell receptor, but these B cells are not able to go through class switch recombination or differentiation to plasma cells in the germinal centre. Therefore, they represent a model for the study of the role of B cells as antigen presenting cells or as effector cells in immune responses, including models of infections. Recent results from our laboratory indicate that B cells have a unique role, apparently quite distinct from antibody production, in the generation of an efficient response to CMV infection (FD and $\mathrm{AW}$, manuscript in preparation).

Acknowledgment This work was funded by the Deutsche Forschungsgemeinschaft grant SFB490 (TPE8) and FP6 Marie Curie Research Training Network MRTN-CT-2004-005632 (IMDEMI).

\section{References}

1. Reddehase MJ (2002) Antigens and immunoevasins: opponents in cytomegalovirus immune surveillance. Nat Rev Immunol 2:831-844

2. Hsieh SM, Pan SC, Hung CC, Tsai HC, Chen MY, Chang SC (2001) Association between cytomegalovirus-specific reactivity of $\mathrm{T}$ cell subsets and development of cytomegalovirus retinitis in patients with acquired immunodeficiency syndrome [see comment]. J Infect Dis 184:1386-1391

3. Lilleri D, Piccinini G, Baldanti F, Seminari E, Galloni D, Gerna G (2003) Multiple relapses of human cytomegalovirus retinitis during HAART in an AIDS patient with reconstitution of CD4+ T cell count in the absence of HCMV-specific CD4+ T cell response. J Clin Virol 26:95-100
4. Rubin RH (1990) Impact of cytomegalovirus infection on organ transplant recipients. Rev Infect Dis 12 Suppl 12(Suppl 7):S754-S766

5. Crawford SW, Longton G, Storb R (1993) Acute graft-versus-host disease and the risks for idiopathic pneumonia after marrow transplantation for severe aplastic anemia. Bone Marrow Transplant 12:225-231

6. Mach M (2006) Antibody-mediated neutralization of infectivity. In: Reddehase MJ (ed) Cytomegaloviruses: molecular biology and immunology. Caister Academic Press, Norfolk (UK), pp 265-283

7. Shanley JD, Jordan MC, Stevens JG (1981) Modification by adoptive humoral immunity of murine cytomegalovirus infection. J Infect Dis 143:231-237

8. Reddehase MJ, Balthesen M, Rapp M, Jonjic S, Pavic I, Koszinowski UH (1994) The conditions of primary infection define the load of latent viral genome in organs and the risk of recurrent cytomegalovirus disease. J Exp Med 179:185-193

9. Farrell HE, Shellam GR (1991) Protection against murine cytomegalovirus infection by passive transfer of neutralizing and nonneutralizing monoclonal antibodies. J Gen Virol 72(Pt 1):149-156

10. Jonjic S, Pavic I, Polic B, Crnkovic I, Lucin P, Koszinowski UH (1994) Antibodies are not essential for the resolution of primary cytomegalovirus infection but limit dissemination of recurrent virus. J Exp Med 179:1713-1717

11. Polic B, Hengel H, Krmpotic A, Trgovcich J, Pavic I, Luccaronin P, Jonjic S, Koszinowski UH (1998) Hierarchical and redundant lymphocyte subset control precludes cytomegalovirus replication during latent infection. J Exp Med 188:1047-1054

12. Klenovsek K, Weisel F, Schneider A, Appelt U, Jonjic S, Messerle M, Bradel-Tretheway B, Winkler TH, Mach M (2007) Protection from CMV infection in immunodeficient hosts by adoptive transfer of memory B cells. Blood 110:3472-3479

13. Cerny A, Sutter S, Bazin H, Hengartner H, Zinkernagel RM (1988) Clearance of lymphocytic choriomeningitis virus in antibody- and B-cell-deprived mice. J Virol 62:1803-1807 
14. Fillatreau S, Radbruch A (2006) IRF4 - a factor for class switching and antibody secretion. Nat Immunol 7:704-706

15. Ahuja A, Shupe J, Dunn R, Kashgarian M, Kehry MR, Shlomchik MJ (2007) Depletion of B cells in murine lupus: efficacy and resistance. J Immunol 179:3351-3361

16. Kessel A, Rosner I, Toubi E (2008) Rituximab: beyond simple B cell depletion. Clin Rev Allergy Immunol 34:74-79

17. Hunt KE, Reichard KK (2008) Diffuse large B-cell lymphoma. Arch Pathol Lab Med 132:118-124

18. Kitamura D, Roes J, Kuhn R, Rajewsky K (1991) A B cell-deficient mouse by targeted disruption of the membrane exon of the immunoglobulin mu chain gene. Nature 350:423-426

19. Mozdzanowska K, Furchner M, Maiese K, Gerhard W (1997) $\mathrm{CD} 4+\mathrm{T}$ cells are ineffective in clearing a pulmonary infection with influenza type A virus in the absence of B cells. Virology 239:217225

20. Buendia AJ, Martinez CM, Ortega N, Del Rio L, Caro MR, Gallego MC, Sanchez J, Navarro JA, Cuello F, Salinas J (2004) Natural killer (NK) cells play a critical role in the early innate immune response to Chlamydophila abortus infection in mice. J Comp Pathol 130:48-57

21. Hasan M, Polic B, Bralic M, Jonjic S, Rajewsky K (2002) Incomplete block of $\mathrm{B}$ cell development and immunoglobulin production in mice carrying the muMT mutation on the BALB/c background. Eur J Immunol 32:3463-3471
22. Macpherson AJ, Lamarre A, McCoy K, Harriman GR, Odermatt B, Dougan G, Hengartner H, Zinkernagel RM (2001) IgA production without mu or delta chain expression in developing B cells. Nat Immunol 2:625-631

23. Gu H, Zou YR, Rajewsky K (1993) Independent control of immunoglobulin switch recombination at individual switch regions evidenced through Cre-loxP-mediated gene targeting. Cell 73:11551164

24. Bradley LM, Harbertson J, Biederman E, Zhang Y, Bradley SM, Linton PJ (2002) Availability of antigen-presenting cells can determine the extent of CD4 effector expansion and priming for secretion of Th2 cytokines in vivo. Eur J Immunol 32:2338-2346

25. Jung S, Unutmaz D, Wong P, Sano G, De los Santos K, Sparwasser T, Wu S, Vuthoori S, Ko K, Zavala F et al (2002) In vivo depletion of $\mathrm{CD} 11 \mathrm{c}(+)$ dendritic cells abrogates priming of CD8(+) T cells by exogenous cell-associated antigens. Immunity 17:211-220

26. Buch T, Heppner FL, Tertilt C, Heinen TJ, Kremer M, Wunderlich FT, Jung S, Waisman A (2005) A Cre-inducible diphtheria toxin receptor mediates cell lineage ablation after toxin administration. Nat Methods 2:419-426

27. Waisman A, Kraus M, Seagal J, Ghosh S, Melamed D, Song J, Sasaki Y, Classen S, Lutz C, Brombacher F et al (2007) IgG1 B cell receptor signaling is inhibited by $\mathrm{CD} 22$ and promotes the development of B cells whose survival is less dependent on $\operatorname{Ig}\{$ alpha $\} /\{$ beta $\}$ J Exp Med 204:747-758 